Document downloaded from:

http://hdl.handle.net/10251/47643

This paper must be cited as:

Andrade Morelli, S.; Ruiz Sanchez, E.; Sendra, S.; Lloret, J. (2013). Router Power Consumption Analysis: Towards Green Communications. Lecture Notes of the Institute for Computer Sciences, Social Informatics and Telecommunications Engineering. 113:28-37. doi:10.1007/978-3-642-37977-2_3.

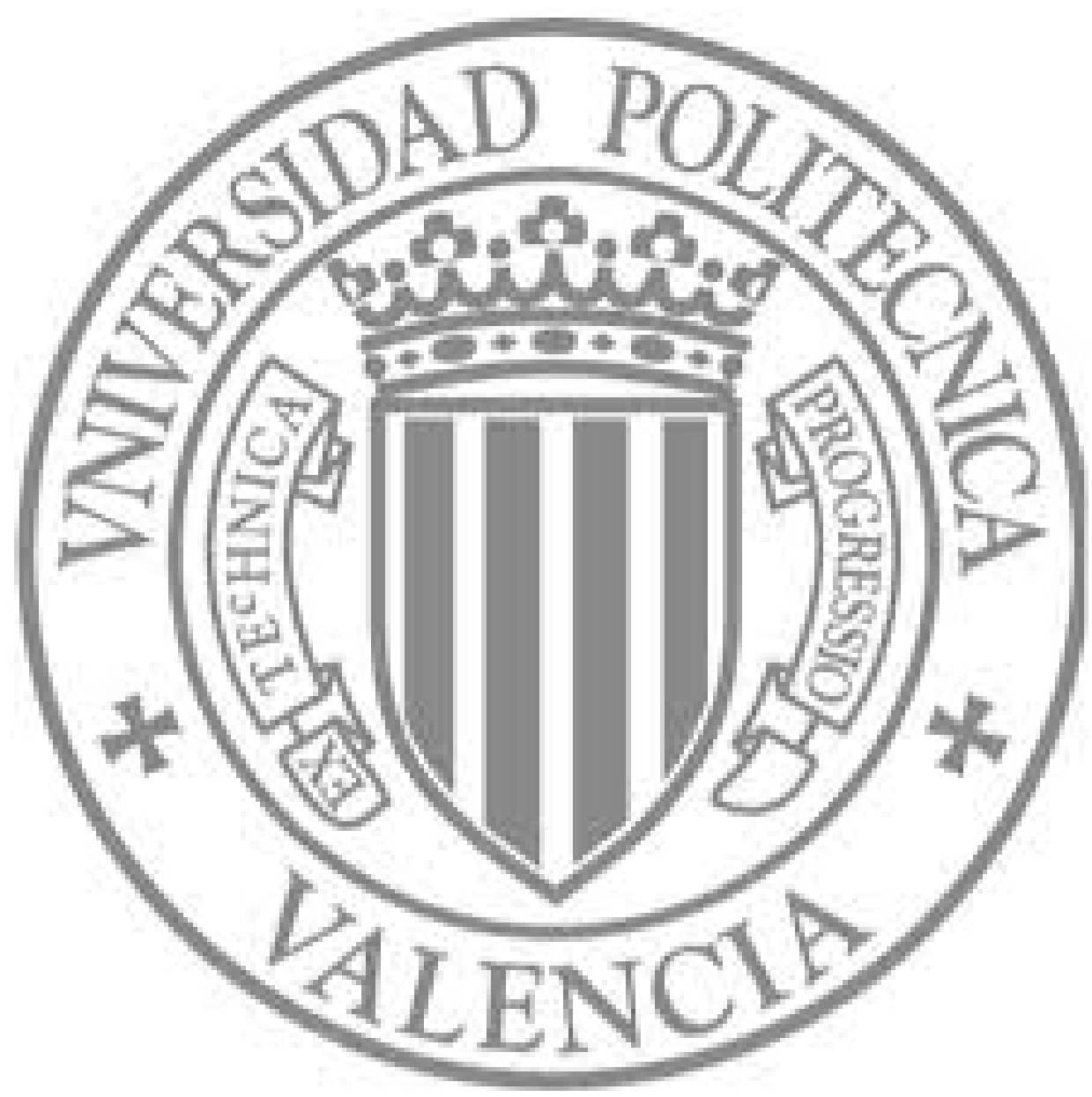

The final publication is available at

http://dx.doi.org/10.1007/978-3-642-37977-2_3

Copyright Springer Verlag 


\title{
Router Power Consumption Analysis: Towards Green Communications
}

\author{
Sebastián Andrade-Morelli, Eduardo Ruiz-Sánchez, Sandra Sendra, Jaime Lloret \\ Universidad Politécnica de Valencia, \\ Camino Vera s/n, 46022, Valencia, Spain \\ seanmodepsg.upv.es, edruisandepsg.upv.es, \\ sansencolposgrado.upv.es, jlloret@dcom.upv.es
}

\begin{abstract}
In recent years, the number of network devices which are being used in new network infrastructure and intelligent buildings, are growing more and more. Because these devices can often have high processing activity, we must consider their power consumption. Their energy requirements may vary depending on their operation mode, their processing capacity and even the type of devices to which are connected. The ability to determine exact consumption of network can provide an optimal network design and the other auxiliary systems, such as cool system, which may be necessary for the proper operation of the network. In this paper we determine the power consumption generated by network devices of different manufacturers and models. These tests allow us to see the energy consumed when they are in await mode and when they are working, running a routing protocol in order to interconnect different networks, promoting the development of the sustainable Green Networks.
\end{abstract}

Keywords: Power Consumption, Routers, Switches, Green Networks.

\section{Introduction}

The increase of mobile devices and the advancement of new technologies, with the possibility to access data networks and Internet, have led us to increase the network infrastructure.

In recent years, there has been an increment of the number of smart phones [1], capable to access to Internet through mobile phone network through wireless access to public networks in cities and public places, which offer this service, improving customer convenience. The implementation of new network services such as data, IP Telephony, IPTV, etc. [2], has also generated the need to increase the number of network devices such as switches and routers. As a consequence of this increment, it has had an increment of the energy consumption in the entire system. We should note that the network devices work better within a temperature range. The range specified by manufacturers is usually between $0-40{ }^{\circ} \mathrm{C}[3,4]$, but the exact value of the operating temperature may change depending on the device or even the task that is running. This factor is important, because the cooling systems must be designed taking into account the correct operating temperature of the devices. A ventilation system should cool a system that generates much heat, should be more powerful, 
which will mean higher energy consumption. Given these facts, the energy saving is vital when trying to implement sustainable networks, where the network must never die [5].

Currently, new energy solutions based on the introduction of IP transmission protocol to all areas of the network are being implemented. The migration of these systems to the next generation networks (NGN) generates a saving energy between 30 and $40 \%$ [6]. Furthermore, the incorporation of routing systems and IP switching improve the energy efficiency of data transmission networks and voice transmission, where there has been a reduction of the requirements of the network capacity between 60 and $70 \%$ [6]. Although other systems such as energy-aware routing protocols, that are being employed in other research fields like in Mobile Ad-hoc Networks [7]), or traffic control systems, to improve the performance [8], we really think that the best way to reduce the energy consumption is to take care of what is being configured in the network devices.

In this paper, we intend to measure the energy consumption of several network routers, depending on its operation mode and the routing protocol that is running (each routing protocol has specific operation features) [9]. In addition, we want to check, if the amount of heat generated by each device is directly related to the device activity. These measures will provide a highly reliable tool for the optimal design of networks and the choice of the most appropriated routing protocol.

The rest of paper is structured as follows. Section 2 presents some previous work and researches regarding to consumption estimation and saving energy in network devices. To perform our tests, we have mounted a network topology, consisting of various network devices. Section 3 shows the topology and characteristics of the used devices. In Section 4 we show the obtained measures from the different tests. Finally, conclusions and future work will be shown in Section 5.

\section{Related Works}

There is great interest in the analysis of the energy consumption of network devices because the excessive consumption can lead to unexpected and rapid failure of the network.

In [10], S. Sendra et al. presented a survey on power saving techniques and energy issues in wireless sensor networks. They also performed a comparison of several routing protocols and MAC protocols to be used in ad-hoc networks (taking into account their energy constraints).

Other authors have focused their analysis on the energy consumption from the point of view of the development of software tools. These tools aim to help in the control of the consumption of our networks as it is the case of those programmed applications for estimating power consumption of network devices such as routers, switches, etc. The report published in November of 2011 [11] shows a comparative of applications that estimate the power consumption of devices. However, the document indicates that the results provided by this software are not very accurate (they compare their values with the ones gathered from the real power consumption). Therefore, we must understand these tools as approximation tools, that can help us to 
do an initial design of our system, but they can never replace actual measurements over real devices.

Due to the recent emergence of new network services and applications, networks are growing, regarding to the number of devices. The increase of the number of network devices also implies an increment of the power consumption. In 2009, M. Kakemizu et al. [12] discuss the possibility of keeping the energy consumption in 2025 at the same level as nowadays by reducing the number of equipments and network devices. To do this, authors propose the development of new technologies based on the flow of information going through the network. They propose two mechanisms that allow efficient use of resources. These are called ECO switching and ECO routing. The first one is based on a new model of switching packets that eliminates the packet buffers and routing tables. The second mechanism includes some paths to the routers when the traffic volume is low. This permits them to wait in sleep mode while they do not receive/transmit anything. When a router needs transmit/receive something, it is activated.

Finally, A. P. Bianzino et al. [13] surveyed several strategies to bring the network to the concept of "Green Network" and explained why it is important to close networks to this concept. Authors explain several strategies that would achieve the objectives pursued by a green network. The authors argue that the design strategies should be based on the simplification and unification of the network to avoid excessive network devices. They also propose the implementation of mechanism of selective connection, where routers can turn-off / turn-on depending on their use, and the group of multiple processes and services using virtualization in the same hardware. This is proposed because a single device working at full capacity, consumes less power than several devices running process less complex.

\section{Scenario and Hardware Description}

In order to perform our measurements, we need to test the performance of several routers from different brands and models. In this section we will see the used routers and their characteristics. To determine the consumption, we have used an electronic device, called "Kill a Watt". The device is able to provide direct measurements of voltage, power and current, without the need for further calculations. The power consumption is given with an accuracy of $1 \%(0.2 \mathrm{~W})$. The section also describes the used topology and the study cases used to take measurements.

To carry out the measures, we used a network topology consisting of four routers, two switches and four computers. Fig. 1 shows the topology used for our purpose. As we can see, the routers are responsible for splitting the networks.

Static routing protocols are often used for small networks, where there are no redundant paths and where there is only one point of attachment to the rest of the network. A dynamic routing protocol is used, if any of the aforementioned conditions is not met. Dynamic routing protocols, allow routers to exchange information. From this information, a router can modify and update their routing tables. In our tests, we have used static routing and the two dynamic routing protocols most used [14]: Routing Information Protocol V.2 (RIP V.2) and Open Shortest Path First (OSPF). In 
each case, we measured the energy consumption of each network device, when devices are in idle state and while it is executing the routing protocol.

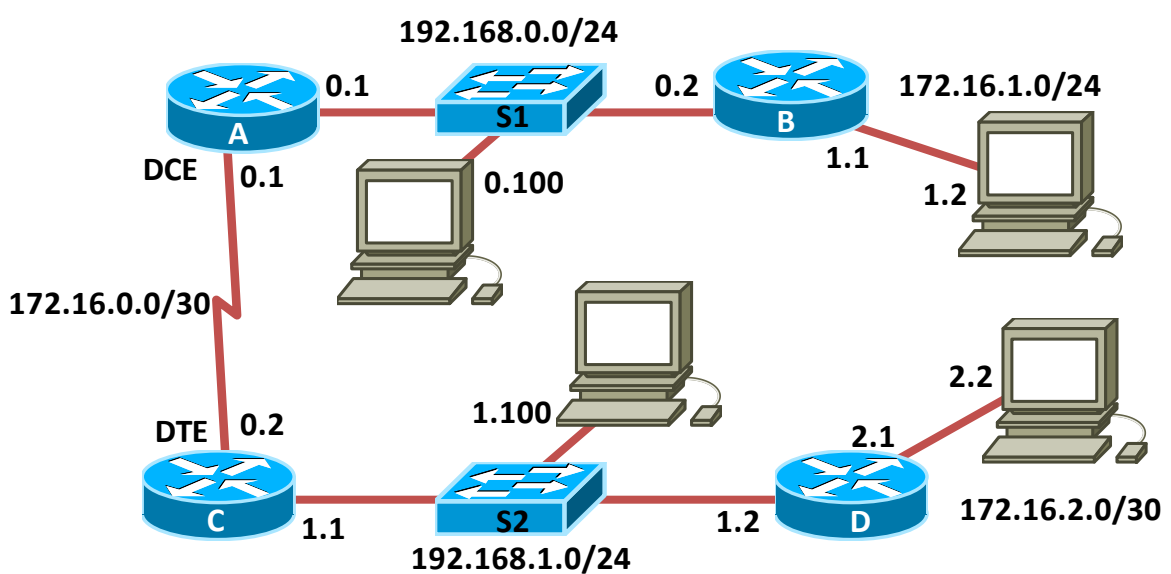

Fig. 1. Network topology.

Network devices used in our test have been Cisco 2620, Cisco 1700 and Cisco 1841, from Cisco Systems Inc, router AR410 from Allied Telesyn and 3Com OfficeConnect Remote 531 Access Router of $3 \mathrm{Com}$. The switch used to connect the routers is Cisco Catalyst 2950. In this paper we do not measure the energy consumption of the switches because they are measured in another study. The purpose of this paper is to measure and compare only routers. The study cases included in this paper are:

- $\quad 1$ st study case: Router Cisco 1841 and switches Cisco 2950.

- 2nd study case: Router Cisco 2620 and switches Cisco 2950.

- 3rd study case: Router Allied AR410 and switches Cisco 2950.

- 4th study case: Router Cisco1700 and switches Cisco 2950.

- 5th study case: Router 3Com Office Connect Remote 531 Access.

Table 1 shows the hardware characteristics of each device. All routers allow the static routing protocol.

Table 1. Hardware features for all devices.

\begin{tabular}{|c|c|c|c|c|c|c|c|}
\hline & $\begin{array}{l}\text { Max Data } \\
\text { transfer Rate } \\
(\text { Gbps })\end{array}$ & $\begin{array}{l}\text { Operating } \\
\text { Temperature } \\
\left({ }^{\circ} \mathrm{C}\right)\end{array}$ & $\begin{array}{l}\text { Internal } \\
\text { memory } \\
(\mathrm{KB})\end{array}$ & $\begin{array}{l}\text { Flash } \\
\text { memory } \\
(\mathrm{KB})\end{array}$ & $\begin{array}{l}\text { Processor (one } \\
\text { processor) }\end{array}$ & $\begin{array}{l}\text { Routing } \\
\text { protocol }\end{array}$ & $\begin{array}{l}\text { Data } \\
\text { Transmission } \\
\text { protocol }\end{array}$ \\
\hline $\begin{array}{l}\text { Allied } \\
\text { AR410 }\end{array}$ & 0.1 & $0-40$ & 16 & 8192 & $\begin{array}{l}\text { Motorola MPC860 } \\
50 \mathrm{MHz} \text { RISC }\end{array}$ & $\begin{array}{l}\text { RIP \& RIP v2, } \\
\text { OSPF }\end{array}$ & $\begin{array}{l}\text { Ethernet, Fast } \\
\text { Ethernet }\end{array}$ \\
\hline $\begin{array}{l}\text { Cisco } \\
1841\end{array}$ & 0.1 & $0-40$ & 191 & 62720 & $\begin{array}{l}\text { Motorola MPC } 860 \\
50 \mathrm{MHz} \text { RISC }\end{array}$ & $\begin{array}{l}\text { RIP \& RIP v2, } \\
\text { OSPF }\end{array}$ & $\begin{array}{l}\text { Ethernet, Fast } \\
\text { Ethernet, serial }\end{array}$ \\
\hline $\begin{array}{l}\text { Cisco } \\
2620\end{array}$ & 0.1 & $0-40$ & 32 & 8192 & $\begin{array}{l}\text { Motorola MPC } 860 \\
50 \mathrm{MHz} \text { RISC }\end{array}$ & $\begin{array}{l}\text { RIP \& RIP v2, } \\
\text { OSPF }\end{array}$ & $\begin{array}{l}\text { Ethernet, Fast } \\
\text { Ethernet, Serial }\end{array}$ \\
\hline $\begin{array}{l}\text { Cisco } \\
1700\end{array}$ & 0.1 & $0-40$ & 32 & 8192 & $\begin{array}{l}\text { Motorola MPC } 860 \\
50 \mathrm{MHz} \text { RISC }\end{array}$ & $\begin{array}{l}\text { RIP \& RIP v2, } \\
\text { OSPF }\end{array}$ & $\begin{array}{l}\text { Ethernet, Fast } \\
\text { Ethernet, Serial }\end{array}$ \\
\hline $3 \mathrm{COM}$ & 0.010 & $0-40$ & 2048 & 2048 & $\begin{array}{l}\text { Motorola MC68360 } \\
25 \mathrm{MHz}\end{array}$ & - & $\begin{array}{l}\text { Ethernet, Serial, } \\
\text { ISDN }\end{array}$ \\
\hline
\end{tabular}




\section{Results}

After configuring the static routing and the 2 routing protocols (if they are available in the router) in all devices, we gathered the measurements obtained. We have summarized these values in several tables and graphs, with the goal of comparing their consumption for different operating conditions. In this section, we will see the results obtained. This will let us determine which set of devices consume less energy. In each case we will only discuss the power consumption of the routers, although we also provide the switches values only for comparison purposes. Switches had approximately $17 \mathrm{~W} \cdot \mathrm{h}$ power consumption all the time (they have not varied).

\subsection{First study case}

First study case test was performed using the router Cisco 1841. Table 2 shows the values of power consumption provided by these devices. Fig. 2 shows the values of power consumption grouped by the protocol configured in the routers. As Fig. 2 shows, the power consumed by all devices is, in all cases, between 16 and $18 \mathrm{~W} \cdot \mathrm{h}$. We also note that the routers $A$ and $C$ have consumption slightly superior than the ones shown by routers $\mathrm{B}$ and $\mathrm{D}$. This may be because, the devices $\mathrm{A}$ and $\mathrm{C}$, are using the serial interface to communicate between them. In addition, we note that the device configured as DTE, consumes about $4 \%$ more power than the DCE device.

Table 2. Results of measurement of $1^{\text {st }}$ case.

\begin{tabular}{lllllll}
\hline Device & \multicolumn{5}{c}{ Power consumption $(\mathrm{W} \cdot \mathrm{h})$} \\
\hline & $\mathrm{A}$ & $\mathrm{B}$ & $\mathrm{C}$ & $\mathrm{D}$ & $\mathrm{S} 1$ & $\mathrm{~S} 2$ \\
Idle Mode & 16.3 & 16.2 & 16.9 & 17.0 & 16.9 & 16.5 \\
RIP Protocol & 17.3 & 16.4 & 17.8 & 17.1 & 17.2 & 16.8 \\
OSPF Protocol & 17.3 & 16.2 & 17.8 & 17.3 & 17.2 & 16.7 \\
Static Protocol & 17.1 & 16.1 & 17.5 & 17.0 & 17.1 & 16.7 \\
\hline
\end{tabular}

Fig. 2. Power consumption for $1^{\text {st }}$ case.

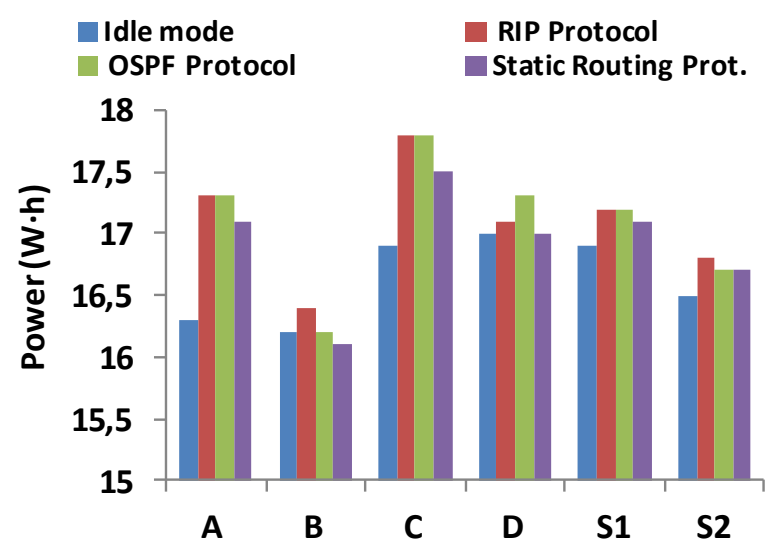




\subsection{Second study case}

Second study case analyzes the behavior of the router Cisco 2620. Table 3 shows the values of power consumption provided by these devices. Fig. 3 shows the power consumption for these devices. In this case, router $\mathrm{A}$ and $\mathrm{C}$ have around $15 \mathrm{~W} \cdot \mathrm{h}$ of power consumption, while the power consumption for routers $\mathrm{B}$ and $\mathrm{D}$ are close to $13.5 \mathrm{~W} \cdot \mathrm{h}$. In this case, the difference of power consumption between the routers $\mathrm{A} / \mathrm{C}$ (with a serial link) and $\mathrm{B} / \mathrm{D}$ (without a serial link) is around $16 \%$.

Table 3. Results of measurement for $2^{\text {nd }}$ case.

\begin{tabular}{lllllll}
\hline Device & \multicolumn{6}{c}{ Power consumption $(\mathrm{W} \cdot \mathrm{h})$} \\
\hline & $\mathrm{A}$ & $\mathrm{B}$ & $\mathrm{C}$ & $\mathrm{D}$ & $\mathrm{S} 1$ & $\mathrm{~S} 2$ \\
Idle Mode & 13.8 & 13.6 & 14.7 & 13.3 & 16.8 & 16.6 \\
RIP Protocol & 14.9 & 13.7 & 15.5 & 13.4 & 17.2 & 16.9 \\
OSPF Protocol & 15.0 & 13.6 & 15.5 & 13.4 & 17.2 & 16.7 \\
Static Protocol & 14.8 & 13.4 & 15.3 & 13.3 & 17.1 & 16.8 \\
\hline
\end{tabular}

Fig. 3. Power consumption for $2^{\text {nd }}$ case.

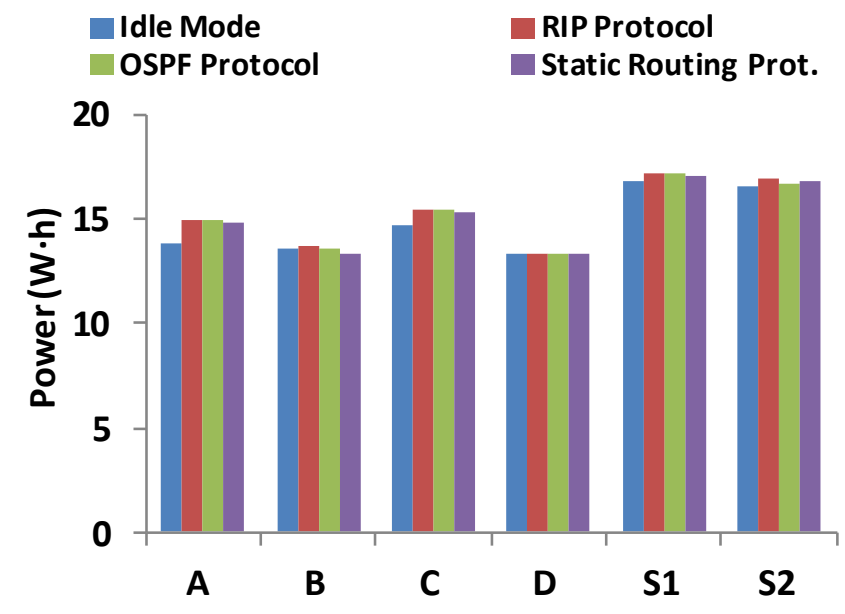

\subsection{Third study case}

Allied AR410 router presents the lowest power consumption of all devices under this test. Table 4 shows the values of power consumption for this case. If we analyze the consumption of all devices, depending on the protocol they are been running, we can see that all routers have power consumption between $6.5 \mathrm{~W} \cdot \mathrm{h}$ (for OSPF in router $\mathrm{C}$, configured as DTE) and $6.8 \mathrm{~W} \cdot \mathrm{h}$ (for RIPV2 in router $\mathrm{C}$, configured as DTE). In idle 
mode, routers maintain their consumption lower than the $6.6 \mathrm{~W} \cdot \mathrm{h}$. These values are shown in Fig. 4.

Table 4. Results of measurement for $3^{\text {rd }}$ case.

\begin{tabular}{lllllll}
\hline Device & \multicolumn{6}{c}{ Power consumption $(\mathrm{W} \cdot \mathrm{h})$} \\
\hline & $\mathrm{A}$ & $\mathrm{B}$ & $\mathrm{C}$ & $\mathrm{D}$ & $\mathrm{S} 1$ & $\mathrm{~S} 2$ \\
Idle Mode & 6.6 & 6.4 & 6.5 & 6.5 & 16.8 & 16.5 \\
RIP Protocol & 6.7 & 6.7 & 6.8 & 6.7 & 17.3 & 17.1 \\
OSPF Protocol & 6.7 & 6.7 & 6.5 & 6.7 & 17.2 & 16.9 \\
Static Protocol & 6.6 & 6.5 & 6.7 & 6.6 & 17.2 & 17.1 \\
\hline
\end{tabular}

Fig. 4. Power consumption for $3^{\text {rd }}$ case.

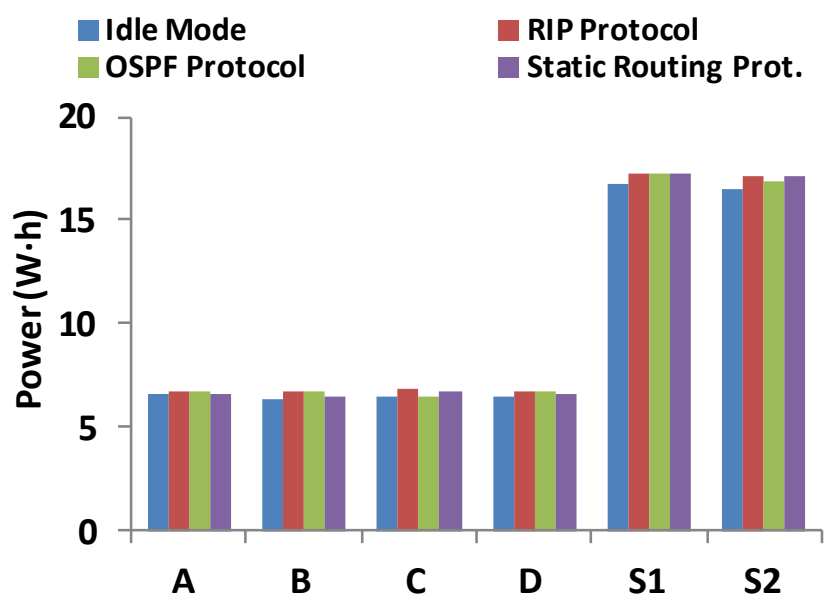

\subsection{Fourth study case}

The fourth case analyzes the consumption of the router Cisco 1700. Table 5 shows the values of power consumption for this device. Fig 5 shows that this Cisco Systems inc. router model consumes less energy than the other models under test. But, it consumes more energy than the Allied Telesyn router model. As we can see, the protocol that consumes more energy is RIP compared with Static routing protocol, where routers consume around $10 \mathrm{~W} \cdot \mathrm{h}(3 \%$ less energy). The router A and $\mathrm{C}$ (with the DCE and DTE connection) consume more energy than routers B and D.

Table 5. Results of measurement for $4^{\text {th }}$ case. 


\begin{tabular}{lllllll}
\hline Device & \multicolumn{5}{c}{ Power consumption $(\mathrm{W} \cdot \mathrm{h})$} \\
\hline & $\mathrm{A}$ & $\mathrm{B}$ & $\mathrm{C}$ & $\mathrm{D}$ & $\mathrm{S} 1$ & $\mathrm{~S} 2$ \\
Idle Mode & 9.6 & 9.2 & 9.9 & 9.1 & 16.7 & 16.6 \\
RIP Protocol & 10.3 & 9.5 & 10.8 & 9.2 & 17.2 & 17.1 \\
OSPF Protocol & 10.1 & 9.3 & 10.6 & 9.2 & 17.2 & 16.9 \\
Static Protocol & 9.9 & 9.0 & 10.1 & 8.8 & 17.1 & 17.0 \\
\hline
\end{tabular}

Fig. 5. Power consumption for $4^{\text {th }}$ case.

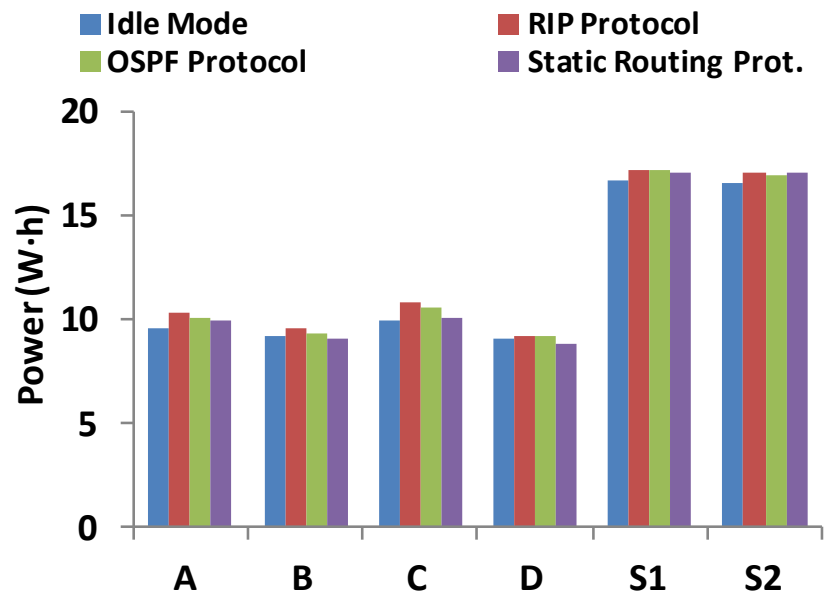

\subsection{Fifth study case}

Finally, we have measured the operation consumption for 3Com Office Connect Remote 531 Access. This model only accepts the static routing protocol. Moreover, the connection between them was using RDSI, so only router A and $\mathrm{C}$ was measured. As Table 6 shows, the routers power consumption is around $11.6 \mathrm{~W} \cdot \mathrm{h}$. Fig, 6 shows these results in a diagram, where it is easy to see the large difference between the routers and switches consumption.

Table 6. Results of measurement for $5^{\text {th }}$ case.

\begin{tabular}{lcccccc}
\hline \multicolumn{1}{c}{ Device } & \multicolumn{5}{c}{ Power consumption $(\mathrm{W} \cdot \mathrm{h})$} \\
\hline & $\mathrm{A}$ & $\mathrm{B}$ & $\mathrm{C}$ & $\mathrm{D}$ & $\mathrm{S} 1$ & $\mathrm{~S} 2$ \\
Idle Mode & 9.1 & - & 9.0 & - & 16.6 & 16.8 \\
Static & 11.5 & - & 11.8 & - & 16.9 & 17.1 \\
Protocol & & & & & & \\
\hline
\end{tabular}

Fig. 6. Power consumption for $5^{\text {th }}$ case. 


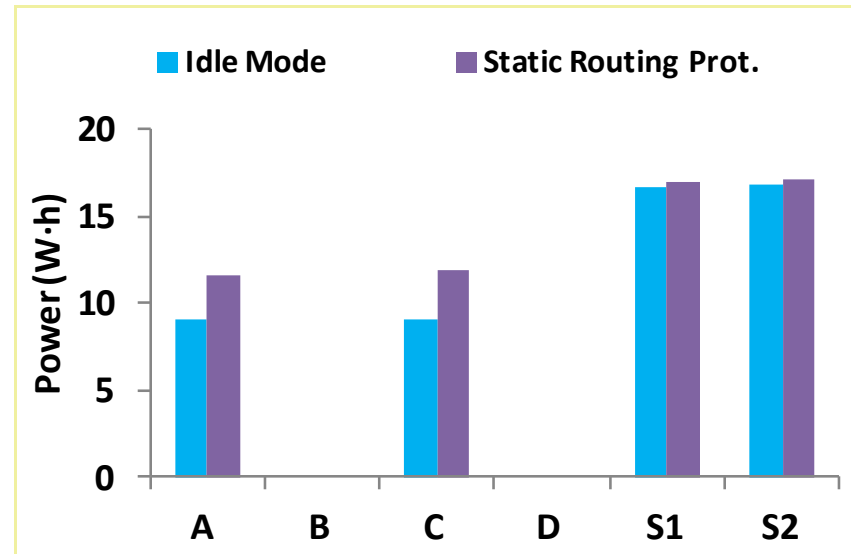

\subsection{Comparative}

Once the tests have been performed, we can determine the combination of devices that consume less energy. As shown in Table 7, the topologies formed with Cisco routers consume more power, compared with Router Allied AR410, which can consume $40 \%$ less power than Cisco Router 1841. Fig. 7 shows these results graphically. As Fig. 7 shows, the model that provides less power consumption is Cisco 1700 (within the three analyzed Cisco router models). It has up to $30 \%$ of less power consumption than Cisco 1841.

Table 7. Total power consumption.

\begin{tabular}{lccccc}
\hline Device & \multicolumn{5}{c}{ Total power consumption (W·h) } \\
\hline & Case 1 & Case 2 & Case 3 & Case 4 & Case 5 \\
Idle Mode & 99.8 & 88.8 & 59.3 & 71.1 & 69.7 \\
RIP Protocol & 102.6 & 91.6 & 61.3 & 74.1 & N/A \\
OSPF Protocol & 102.5 & 91.4 & 60.7 & 73.3 & N/A \\
Static Protocol & 101.5 & 90.7 & 60.7 & 71.9 & 79.4 \\
\hline
\end{tabular}

Fig. 7. Total power consumption. 


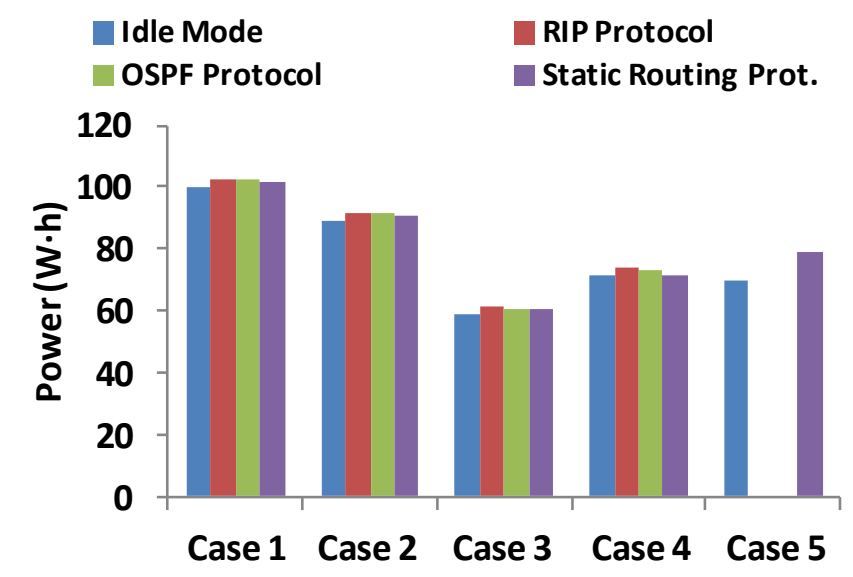

\section{Conclusion}

Saving energy in network devices is being a hot topic in recent years. This is due to the proliferation of the concept of Green Networks and the interest of research groups to develop sustainable networks. Therefore, the first step is to be able to determine the power consumption of these devices.

In this paper, we have performed a power consumption study that different router models consume depending on the routing protocol that is running. As we have seen, the energy consumption depends directly on the device hardware, the configuration capabilities of these and the active interfaces. The difference in consumption between a protocol and another one is small, presenting a maximum difference of $2-3 \%$. The highest values has been obtained for RIP protocol in study case $1(102.6 \mathrm{~W} \cdot \mathrm{h})$, where we had router Cisco 1841, and the lowest one has been the idle mode in study case 3, Allied AR410 router, $(59.3 \mathrm{~W} \cdot \mathrm{h})$. Despite of what people think, OSPF has being consuming less energy than RIP in all cases.

In future work, we would like to analyze the operating temperature of the devices, in function on the routing protocol. With this new analysis we will can to establish several design rules for the cooling systems that these devices need, in order to maintain the entire system at a suitable temperature. Moreover we will also compare several switch models from different manufacturers.

\section{References}

1. Balasubramanian, N., Balasubramanian, A., Venkataraman, A.: Energy Consumption in Mobile Phones: A Measurement Study and Implications for Network Applications. In proceedings of the 9th ACM SIGCOMM conference on Internet measurement conference (IMC '09), Nov. 4-6, Chicago, IL, USA (2009) 
2. Bianco, C., Cucchietti, F., Griffa,G.: Energy consumption trends in the next generation access network - a telco perspective. $29^{\text {th }}$ International Telecommunications Energy Conference (INTELEC 2007), Sept. 30 - Oct. 4, Rome, Italy, (2007)

3. Datasheet of Router Cisco184. Available at Cisco web site: http://www.cisco.com/en/US/ $\mathrm{prod} /$ collateral/routers/ps5853/ps5875/product_data_sheet0900aecd806c4e2a.pdf

4. Datasheet of Router Allied AR410. Available at Alied telesync web site: http://www.alliedtelesis.com/media/fount/datasheet/AR410Series_Datasheet_RevQ.pdf

5. Fisher, W., Suchara, M., Rexford, J.: Greening Backbone Networks: Reducing Energy Consumption by Shutting Off Cables in Bundled Links. In proceedings of the first ACM SIGCOMM workshop on Green networking, Aug. 30, New Delhi, India, (2010)

6. González, N., Moran, L., Angioleti, J. M., Varela, J. A.: Green IT. Chapter 4. Green Telecom Networks. eKISS n⿳802.Internal publication of Telefónica. (2009).

7. Ahlam Hashim Mohsin, Kamalrulnizam Abu Bakar, Adebanjo Adekiigbe, kayhan zrar ghafoor, A Survey of Energy-aware Routing protocols in Mobile Ad-hoc Networks: Trends and Challenges, Network Protocols and Algorithms, Vol 4, No 2 (2012). Pp. 82-107

8. Qiang Duan, Performance Evaluation on Traffic Control in Combined Input and Cross-point Queuing Switches, Network Protocols and Algorithms, Vol 3, No 4 (2011), Pp. 18-31

9. Sendra, S., Fernández, P. A., Quilez, M. A., Lloret, J.: Study and Performance of Interior Gateway IP routing Protocols. Network Protocols and Algorithms. Vol. 2, Issue 4, pp. 88117. (2010)

10.Sendra, S.; Lloret, J.; Garcia, M.; Toledo, J.F.: Power saving and energy optimization techniques for Wireless Sensor Networks. J. Commun. Acad. Publ. 2011, 6, 439-459

11.Cisco Report. Server power calculator analysis: Cisco UCS power calculator and HP power advisor. (2011)

12.Kakemizu, M., Chugo, A.: Approaches to Green Networks. Fujitsu Scientific and Technical Journal. Vol. 45, Iss. 4, pp. 398 - 403. (2009)

13.Bianzino, A.P.; Chaudet, C.; Rossi, D.; Rougier, J.-L.: A Survey of Green Networking Research. IEEE Communications Surveys \& Tutorials, vol.14, no.1, pp.3-20 (2012)

14.W. R. Stevens: TCP/IP Illustrated, Vol. 1: The Protocols (Addison-Wesley Professional Computing Series) (1994) 